\title{
A COOPERAÇÃO NA GOVERNANÇA AMBIENTAL GLOBAL PARA CONSTRUÇÃO DE UMA ARQUITETURA DE PREVENÇÃO DE CONFLITOS EM TORNO DOS RECURSOS NATURAIS
}

\begin{abstract}
Norma Suel Padilha
Doutorado em Direitos Difusos e Coletivos pela Pontifícia Universidade Católica de São Paulo - PUC/SP (2004) e mestrado em Direito das Relações Sociais pela Pontifícia Universidade Católica de São Paulo - PUC/SP (2000). Pós-doutorado em Ética Ambiental pela UNICAMP (2010). Professor Associado da Universidade Federal do Mato Grosso do Sul - UFMS (graduação e pesquisa). Docente do Programa de Mestrado e Doutorado em Direito da Universidade Católica de Santos - Unisantos. Possui experiência na Advocacia Pública (AGU) e na advocacia privada. Autora da obra laureada com o Prêmio Jabuti 2011 na categoria direito: Fundamentos Constitucionais do Direito Ambiental Brasileiro. Membro da diretoria da APRODAB - Associação dos Professores de Direito Ambiental no Brasil. Palestrante e conferencista. Professora colaboradora da Escola Nacional de Formação e Aperfeiçoamento de Magistrados do Trabalho - ENAMAT.
\end{abstract}

Simone Alves Cardoso

Doutoranda em Direito Ambiental Internacional pela Universidade Católica de Santos. Professora de direito civil e mediação na graduação da Faculdade de Direito da Unisantos. Coordenadora do Juizado Especial Civil da Universidade Católica de Santos e Curso de Mediação da Unisantos. Integra o grupo de pesquisa em Energia e Meio Ambiente, da Pós-gradução Mestrado e Doutorado da Unisantos. Conciliadora e mediadora pela EPM/SP.

\section{Resumo}

O presente artigo objetiva demonstrar a efetividade e a importância da cooperação nos arranjos de governança ambiental global para prevenção de conflitos e promoção da paz, por meio da análise da parceria entre a União Europeia (UE) e Organização das Nações Unidas (ONU) em torno dos recursos naturais e prevenção de conflitos. O problema a ser enfrentado e que se coloca como desafio a ser superado pela comunidade internacional é a fragilidade de alguns países em criar e manter instituiçóes capazes de gerenciar e prevenir conflitos violentos por recursos naturais. A pesquisa identifica o papel que a ONU-UE promovem na prevenção desses conflitos. Também, evidencia que as açóes de governança desenvolvidas por estes atores fornecem ferramentas para melhorar a capacidade dos Estados nacionais na tomada de decisóes, quando do gerenciamento e 
tratamento desses conflitos propiciando a possibilidade de resultados que materializam uma arquitetura de governança ambiental global na promoção da paz.

\section{Palavras-chave}

Governança Ambiental global; Cooperação; Prevenção de Conflitos; Recursos Naturais.

\section{Abstract}

This article aims to demonstrate the effectiveness and the importance of cooperation in global environmental governance arrangements to prevent conflicts and promote peacebuilding through analysis the partnership between the European Union (EU) and the United Nations (UN) around the natural resources and conflict prevention. The problem to be addressed and the challenge to overcome by the international community is the fragility of some countries in creating and maintaining institutions to manage and prevent violent conflicts over natural resources. The research identifies the role that the UN-EU promote conflict prevention. This research also shows that governance actions taken by these actors provide tools to improve the ability of national states in making decisions in such conflicts, providing results that materialize a global environmental governance promoting peace.

\section{Key words}

Global Environmental Governance; Cooperation; Conflict Prevention; Natural Resources.

\section{Introdução}

A magnitude transnacional das causas e efeitos dos problemas ambientais exigem que a proteção do meio ambiente seja preocupação de Estados, organizaçóes e instituiçóes internacionais, sociedade civil, dentre outros.

Essa preocupação exige açóes concretas de cooperação entre os diversos atores envolvidos na governança ambiental global. Uma temática primordial nesse contexto é a manutenção da paz, que envolve conflitos ambientais em torno dos recursos naturais.

O conflito, por si só não é um fenômeno negativo, pois o conflito não violento pode ser um componente essencial de mudança social e desenvolvimento. Porém, quando as sociedades possuem instituiçóes fracas e sistemas políticos frágeis, que não conseguem desenvolver mecanismos de gerenciamento e resolução de conflitos, a consequência é 
a instabilidade e a violência. Entretanto, tais contextos em torno dos recursos naturais representam um problema a ser superado pelo Direito Internacional Ambiental.

Assim, um dos desafios e interesse que pode ser objeto de preocupação da comunidade internacional é o fomento de uma governança ambiental global na temática de prevenção e resolução de conflitos, em torno dos recursos naturais, de forma não violenta. Por isso, a importância de se estudar e identificar açóes capazes de promover mudanças na arquitetura dos Estados, fortalecendo suas capacidades de conhecimento em prevenção e resolução de conflitos.

Deste modo, o objetivo do artigo é demonstrar a efetividade e a importância da cooperação nos arranjos de governança ambiental global para promoção da paz nos recursos naturais, especificamente por meio de uma análise da parceria entre a União Europeia (UE) e Organização das Naçóes Unidas (ONU) em torno dos recursos naturais e prevenção de conflitos.

No decorrer da pesquisa buscaremos responder a duas questóes que emergem desta parceria. Qual o papel da ONU e UE na prevenção de conflitos em torno de recursos naturais? E se os resultados promovidos por tal parceria se mostram aptos a contribuir para uma melhoria da capacidade dos Estados na solução de conflitos por meio da cooperação e da prevenção?

Para tanto, na primeira parte, descreveremos conceitos relacionados a governança no âmbito do Direito Internacional Ambiental, enfocando a importância da cooperação em matéria ambiental internacional.

Num segundo momento, será descrito o contexto da criação da parceria entre ONU e UE, em torno dos recursos naturais e prevenção de conflitos, desde a sua formação, perpassando pelo seu objeto de estudo, compreensivo de questóes e conflitos relacionados a terra, recursos naturais e prevenção de conflitos. Após, passa-se a análise de seu principal objetivo, que é desenvolver e implantar um projeto estratégico interinstitucional focado na construção da capacidade de governança ambiental dos agentes nacionais, do sistema das Naçōes Unidas e da União Europeia.

Por último, abordaremos os resultados, que marcam o papel chave dessas agências no domínio de prevenção de conflitos em torno dos recursos naturais, pois a cooperação permitiu a formulação de uma plataforma comum de conhecimento nesta temática. Igualmente, importante, é a identificação da capacidade da parceria ONU-EU, em fomentar a criação de uma arquitetura com estratégias, orientações e ferramentas que devem ser implantadas por Estados quando da identificação de possíveis conflitos violentos que envolvam os recursos naturais, materializando uma governança eficaz na prevenção e pacificação de conflitos. 
A metodologia do trabalho no início é pelo método indutivo, seguida de uma abordagem descritiva, realizada por intermédio de estudo, análise, registro e interpretação dos dados produzidos pela parceria entre a Uniāo Europeia e Organizaçóes das Naçóes Unidas, Relatórios do Secretário Geral, dentre outros trabalhos oriundos da aliança, além de obras de referência.

\section{Governança no Direito Ambiental Internacional}

Um dos regimes mais recentes do regramento jurídico internacional é o Direito Internacional Ambiental, que aglutina uma normativa cada dia mais ampla, diversificada e complexa. (KISS, 2005, p. 5)

O Direito Internacional Ambiental compartilha com o Direito Internacional geral seus principais elementos estruturais, mas, em razão da peculiaridade de seu objeto, o meio ambiente, o Direito Internacional do Meio Ambiente apresenta características particulares, marcado por uma fisionomia jurídica peculiar, como funcionalidade, multidimensionalidade, participaçáo de atores náo estatais e ampla presença de soft law na proteção de interesses gerais. (RUIZ, 2014, p. 35)

A finalidade do Direito Internacional do Meio Ambiente é inequivocamente o interesse geral da humanidade e os Estados devem cooperar para servir esse interesse (BEURIER, 2010, p.29).

Seguindo a linha de Ruiz (2014, p.36), os Estados têm percebido a necessidade de cooperar em busca de soluçôes de problemas graves que afetam o meio ambiente comum. São três os problemas relatados pelo autor, que póe em evidência a internacionalização dos problemas ambientais e a necessidade de cooperação na busca de resoluçôes. São eles, a contaminação transfronteiriça, a exportação dos riscos ou mundialização dos problemas ambientais e a crescente globalização do sistema econômico.

A cooperação é um dos primeiros princípios do Direito Internacional Ambiental e foi proclamado na Declaraçáo de Estocolmo de 1972, cujo artigo 24 afirma que "todos os países, grandes e pequenos, devem ocupar-se com espírito de cooperação e em pé de igualdade com as questóes internacionais relativas à proteçáo e melhoramento do meio ambiente”. A Rio/92, também, abordou em vários de seus princípios, a necessidade de cooperação internacional.

Segundo Ruiz (2014, p.48), o princípio da cooperação implica também outros deveres, tais como promover a investigação cientifica e tecnológica, promover assistência técnica e financeira aos países necessitados e estabelecer programas de vigilância e evolução ambiental. Ressalta que estes objetivos devem ser desenvolvidos no plano mundial, regional e local, bem como que a direçáo dos mesmos deve ficar aos cuidados de organizaçóes internacionais competentes. 
No mesmo sentido, Padilha (2010, p. 267) menciona a importância da solidariedade na tarefa da cooperação ao afirmar que:

O princípio da cooperaçáo deixa claro que a conquista da efetividade do direito ao meio ambiente ecologicamente equilibrado, necessita de uma rede solidária de açôes proativas, coordenadas, conjuntas, a envolver desde os entes políticos estatais, no nível internacional e interno de cada país, bem como toda sociedade civil organizada e cada indivíduo isoladamente considerado.

Assim, o Direito Internacional Ambiental exige uma transformação nas relaçóes entre Estados e outras estruturas de governo e de governança, que possa expressar os objetivos de cooperaçáo. Um processo que permite o adequado tratamento dos problemas ambientais e uma interação entre vários atores na busca de soluçóes é a governança ambiental global.

Segundo Biermann e Pattberg (2012, p.4) no âmbito nacional, o conceito de governança geralmente implica algum grau de autorregulação por parte de atores sociais, a cooperação público-privado na resolução de problemas sociais e novas formas de política multinível. A noção de governança global é mais recente. Baseia-se em debates anteriores entre cientistas políticos que trabalham em questóes nacionais e tentam aplicar desenvolvimentos semelhantes no plano internacional.

Seguindo o raciocínio de Biermann (2012, p.4), o conceito busca diferenciar dois grandes usos do termo governança global. O primeiro, usado analiticamente como uma descrição das transformações sociopolíticas atuais. O segundo conceito é usado normativamente como uma descrição do programa político que lida com os desafios da globalização.

Bem orienta Gonçalves (2011, p.85), ao fazer a distinção de governança em sentido amplo e restrito. "Em sentido amplo, governança refere-se à arquitetura do sistema onde está inserida", menciona a necessidade de se estabelecer arranjos institucionais capazes de gerenciar problemas comuns de forma consensual.

Já em termos mais restritos, o autor menciona (2011, p.86) que a governança pode ser resumida em quatro dimensóes, assim descritas:

Caráter instrumental, de meio e processo capaz de produzir resultados eficazes diante de problemas comuns; a participação ampliada; o predomínio do consenso e da persuasão nas suas práticas e a existência de um conjunto de normas e regras a sustentá-la.

Essa reorganização do poder, a interdependência e a interconexão na esfera global é perceptível no desenvolvimento e evolução das várias Conferências das Nações Unidas para 
o Meio Ambiente e Desenvolvimento Sustentável (1972, Estocolmo; 1992, Rio Janeiro; 2002, Joanesburgo; 2012, Rio+20) e que fundamentam o Direito Ambiental Internacional e o surgimento da governança ambiental global, que é a intersecção da governança global com as questóes ambientais.

As possíveis carências do Direito Internacional Ambiental, segundo Ruiz (2013, p. 90) não derivam de escassez de normas nem de sua intensidade jurídica, mas sim do insuficiente grau de cumprimento das mesmas. Para o autor, esta situação "resulta da falta de instituiçôes capazes de assegurar uma governança multilateral". O organismo que hoje se ocupa desta questão é o Programa das Nações Unidas para o Meio Ambiente (PNUMA) estabelecido pela Conferência de Estocolmo (1972). O PNUMA foi criado pela Assembleia Geral como órgão subsidiário e é o principal órgão das Nações Unidas no âmbito do meio ambiente e desenvolvimento sustentável.

Segundo Padilha (2010, p.58), o PNUMA “atua como agente catalizador, estimulando os outros a agirem, e trabalhando em conjunto com outras organizaçóes, incluindo Agências das Naçóes Unidas e Governos". Assim, o processo de governança envolve uma gama de parceiros, incluindo organizaçóes internacionais e sub-regionais, governos nacionais, estaduais, municipais, organizaçóes não governamentais, setor privado e acadêmico.

Sua função principal, dentre outras, é promover a cooperação internacional no âmbito do meio ambiente e recomendar politicas nesta matéria. Ao longo do tempo, já foram realizados vários esforços para criar uma estrutura internacional de governança global dotada de poderes mais efetivos, tendo em vista os limitados recursos financeiros, disponíveis para a administração do PNUMA. Nos preparativos dos trabalhos da Rio+20, a criação de uma organização internacional do meio ambiente foi objeto de discussão. Mas, ao final, o documento "O futuro que queremos" reforçou o papel do PNUMA. (RUIZ, 2014, p.91-92)

Assim, reconhecendo que a governança ambiental, nos âmbitos nacional, regional e global é fundamental para a consecução da sustentabilidade ambiental e do desenvolvimento sustentável, o PNUMA criou um subprograma de governança ambiental.

Dentre os objetivos do subprograma, podemos citar os objetivos de organizar uma vasta gama de parceiros para abordar os fatores mais essenciais em busca de alcançar o progresso em direção a processos de tomada de decisóes internacionais coerentes para a governança ambiental, adequar capacidades para alcançar os objetivos acordados internacionalmente e prioridades ambientais nacionais por meio de medidas legais e institucionais adequadas e promover a integração da sustentabilidade ambiental no desenvolvimento em todos os níveis, incluindo regional, sub- regional e nacional. (UNEP, 2013)

Desta forma, os atuais problemas ambientais globais exigem uma nova forma de governar os desafios com complementariedade e coexistência entre o sistema tradicional de resolução de conflitos e a governança ambiental global. 
Um dos papéis primordiais da atuação da PNUMA é fornecer suporte aos governos para traduzir as decisóes ambientais internacionais em açóes específicas no âmbito nacional e local, diminuindo assim a discrepância entre os compromissos, como os expressos em Acordos Ambientais Multilaterais (AAM), e sua implementação.

Para alcançar uma abordagem integrada para o desenvolvimento sustentável, o PNUMA promove a integração da sustentabilidade ambiental nos processos de desenvolvimento nacionais e regionais.

A cooperaçáo entre os diversos atores envolvidos na governança ambiental global é uma das açóes efetivas do PNUMA. Uma temática primordial nesse contexto é a manutenção da paz, que envolve disputas ambientais em torno dos recursos naturais. Muitos conflitos estão diretamente relacionados ou são alimentados por disputas em torno dos recursos naturais, mas os fatores ambientais e os recursos naturais não são a única causa dos conflitos. Geralmente, esses fatores interagem com fatores econômicos, políticos e de segurança.

O conflito náo deve ser visto apenas de forma negativa pois ele pode ser um fator de mudança e desenvolvimento. O conflito pode ser abordado como uma oportunidade para construção de cooperaçáo e confiança entre grupos divididos e para o estabelecimento de relaçóes fortes entre os diversos níveis de governo.

Uma oportunidade de resolução para a escalada de possíveis conflitos seria o fortalecimento das instituiçôes encarregadas de resolução de conflitos, para efetivar uma governança ambiental pacificadora.

Nesse contexto, podemos citar como exemplo, de ação conjunta em busca de concretizar objetivos comuns, o Projeto de parceria global da ONU e EU no terreno de recursos naturais e prevenção de conflitos. Essa parceria reúne agências e departamentos da ONU (DESA, DPA, PBSO, habitat, OIM, PNUD e UNEP), em cooperação com a Uniáo Europeia e que, apoiados por experiências de campo da sociedade civil e organizaçôes não governamentais, desenvolvem conhecimento na gestão dos recursos naturais para prevenção de conflitos e construçáo da paz. Esses conhecimentos serão a base para promover a capacidade de outros Estados em lidar com conflitos em torno dos recursos naturais.

\section{Formação da Parceria entre Organizações das Nações Unidas (ONU) e União Europeia (UE), no Terreno dos Recursos Naturais e Prevenção de Conflitos}

Tendências mundiais como mudanças demográficas, aumento de consumo, degradação do meio ambiente e mudanças climáticas estão exercendo pressão e gerando 
instabilidade sobre a disponibilidade e a capacidade de utilização dos recursos naturais, como aqueles relacionados ao uso e ocupação da terra, a água e a preservação e conservação dos ecossistemas. Quando esses fatores estão associados com questôes políticas, econômicas e sociais os problemas relacionados aos recursos naturais tendem a se converter em conflitos destrutivos e potencialmente violentos, com consequências graves para vida e para os meios de subsistência.

Para enfrentar tais problemas, e incentivados por orientaçóes das Assembleia Geral da ONU no sentido de fortalecer a governança ambiental entre organizaçóes nacionais, regionais e internacionais, a União Europeia (UE) e as Naçóes Unidas (ONU) estabeleceram, em 2008, uma parceria de cooperaçáo com o objetivo de fomentar a capacidade dos Estados de prevenir conflitos que envolvem recursos naturais.

A abordagem da parceria se baseia na compreensão de que os recursos naturais podem sustentar o desenvolvimento, promover estabilidade e determinar estilos de vida. No entanto, se esses recursos naturais forem mal geridos, podem desencadear baixo crescimento, corrupção, erosão da autoridade do Estado e conflitos destrutivos. Assim, a capacidade de promover uma boa governança ambiental em torno dos conflitos por recursos naturais é um dos elementos essenciais para consolidação da paz.

Esta parceria materializa as novas formas de cooperação que tem se desenvolvido na governança ambiental internacional, que inclui os governos, as organizaçóes internacionais (OI), organizações náo-governamentais (ONGs), o setor corporativo, e, até mesmo, indivíduos (poderosos) como atores. A maioria desses processos de colaboração engloba múltiplas formas de inovação institucional, e muitas maneiras informais e voluntárias para resolver os desafios e problemas ambientais.

\section{Objetivos da Parceria entre ONU e UE no Terreno dos Recursos Naturais e Prevenção de Conflitos}

Dentre os diversos desafios que permeiam os países em desenvolvimento, podemos destacar a questão relacionada à gestão da terra e dos recursos naturais. Essa deve ser uma preocupação para todos os países que pretendem prevenir conflitos e alcançar um desenvolvimento que promova a paz ambiental.

Para atender a esta preocupação a ação conjunta da União Europeia e ONU surgiu com o objetivo de fomentar a capacidade desses atores e seus países parceiros em prevenir, gerir e resolver conflitos relacionados a terra e aos recursos naturais.

Esse objetivo está fundamentado no convencimento de que os recursos naturais podem sustentar o desenvolvimento por meio do equilíbrio dos meios de subsistência, porém, quando mal administrados, podem gerar resultados negativos, como déficit 
no crescimento, corrupção, instabilidade no poder do Estado e conflitos destrutivos. (PNUD, 2013, p.5)

No mesmo sentido, o Programa das Naçôes Unidas pesquisou situaçóes de conflitos para traçar a importância da gestão dos recursos naturais para a consolidação da paz. Essa pesquisa desenha algumas conclusóes para futuras operaçôes das Nações Unidas de pacificação e consolidação da paz, das quais destacamos três. A primeira conclusão é de que os recursos naturais e o meio ambiente podem ser envolvidos em todas as fases do ciclo de conflito, a segunda é de que podem contribuir para o aparecimento e perpetuação do conflito dificultando as perspectivas para a paz. (UNEP, 2009, p.27)

A terceira conclusão indica que a maneira como os recursos naturais e o meio ambiente são geridos tem uma influência determinante na paz e segurança. Assim, por conseguinte, é evidente que o investimento em gestão ambiental e dos recursos naturais é um investimento na prevenção de conflitos. Além disso, a cooperação em matéria de gestão dos recursos naturais proporciona novas oportunidades para a construção da paz. (UNEP, 2009, p.28)

Assim, a parceria da ONU e UE, pretende potencializar a governança aumentando suas capacidades de conhecimento nesse assunto. A materializaçáo deste resultado pode ser constatada pela produção de um documento que orienta as açóes de campo, com treinamentos de pessoas e divulgação dos casos.

Dessa forma, fortalecer a capacidade das instituiçóes de governo e da sociedade civil relacionadas com a gestão dos conflitos da terra e dos recursos naturais é essencial para o êxito dos esforços de prevenção, recuperação e consolidação da paz. Também, é fundamental para superar as dificuldades de aplicação efetiva do Direito Internacional Ambiental, pois como evidencia Ruiz (2014, p.89) essa dificuldade decorre de um "escasso nível de desenvolvimento institucional dos mecanismos de governança”.

Assim, esses esforços e respostas são desafios que devem ser enfrentados por meio da governança ambiental global, promovendo o empoderamento e a legitimidade dos atores envolvidos.

O papel da parceria ONU-EU em torno dos recursos naturais e prevenção de conflitos é dar suporte aos Estados, por meio de uma plataforma comum de conhecimento, para que estes possam agir no âmbito internacional, nacional e local, de acordo com as melhores práticas sugeridas no material e nos treinamentos disponíveis nessa plataforma de conhecimento.

A parceria ONU-EU evidencia a cooperação e a governança ambiental global, sob dinâmica do Direito Internacional Ambiental, pois é concreta e essencial a participação de diversos atores públicos e privados como indústria, autoridades e comunidades locais 
na construção de um conhecimento científico para o enfrentamento de conflitos. Uma rede que envolve vários níveis, atores e papéis para consecução da paz.

Segundo Gonçalves e Costa (2015, p.102) “uma das características mais importantes da governança ambiental global é a presença de múltiplos atores em seu processo de diagnóstico, construção, implementação e monitoramento".

Um dos desafios para concretização dos objetivos da parceria entre ONU-EU é conciliar os diversos interesses, entre os principais atores deste processo, de forma a garantir que a articulação entre eles se torne efetiva e resulte em açóes claras que contribuam para pacificação.

\section{Resultados da Parceria ONU-UE no Terreno dos Recursos Naturais e Pre- venção de Conflitos}

A cooperação estabelecida pela parceria ONU-EU permitiu a construção de uma plataforma comum entre as agências, no domínio de prevenção de conflitos.

Os primeiros resultados desse projeto são um inventário de ferramentas ${ }^{1}$ e capacidades dentro do sistema das Nações Unidas e um conjunto de Notas de Orientação sobre a gestão dos recursos naturais e prevenção de conflitos, acompanhado de materiais de treinamento e um módulo de formação on-line interativa. Os tópicos que abordam essas notas de orientação são: a terra e os conflitos; as indústrias extrativas; os recursos renováveis e conflito; fortalecer a capacidade para gestão sustentável de terras e recursos naturais.

Também, produziu um texto chamado "recursos de inventário das capacidades disponíveis para a gestáo consensual e sustentável da terra e dos recursos naturais" dentro do Sistema das Naçóes Unidas. Esse inventário define e avalia a capacidade das Naçôes Unidas para promover a gestão pacífica e inclusiva de conflitos como: (UNEP/ Capacity Inventory, 2010, p.8)

A capacidade de identificar potenciais situaçóes de risco para o conflito, e a introdução de medidas preventivas que possam contribuir para o desenvolvimento de capacidades na gestão pacífica de recursos naturais. Essa capacidade abrange as condiçóes funcionais que permitem que o sistema das Naçôes Unidas possa elaborar e implementar programas. Os diferentes componentes da capacidade podem ser organizados ao longo de um ciclo de quatro estágios. Esse ciclo se move a partir de (1) Informação [Monitoramento, Análise, Pesquisa, Intercâmbio de Informaçóes], a (2) Formulação da Estratégia [Política de orientação, formaçáo, Apoio Operacional], (3) Implementação [campo/nível de Iniciativas] e (4) Aprendizagem. (Tradução livre do autor)

1 Kit de herramientas y orientación para la prevención y gestón de conflitos de tierras y recursos naturales. 
Esse inventário buscou aplicar todas as dimensôes do conceito de capacidade de prevenção de conflitos, que se desenvolve em ciclos (Informação, Formulação de estratégia, Implementação e Aprendizado), no trabalho desenvolvido por todos os atores que participam da parceria ONU-EU.

Assim, a formulação de um material de orientação descrevendo experiências e melhores práticas, surge como uma ferramenta importante que dará suporte a tomada de decisóes por parte de governos e comunidade internacional, no domínio da gestão da terra e dos recursos naturais a nível global.

Um exemplo de boas práticas em matéria de gestão de recursos naturais, indicado no material disponibilizado para os Estados, diz respeito a como conciliar interesses entre indústria, autoridades e comunidades locais por meio do diálogo e da participação de todos os atores na gestão dos recursos naturais, nesse aspecto os Estados podem contar com a experiência da Unidade de Mediação da ONU, ligada ao Departamento de Assuntos Políticos da ONU, que é organização parceira do projeto

Deste modo, concluímos que a cooperação entre estes atores produziu resultados, que ajudam os Estados a melhorarem sua capacidade de decisão, pois a capacidade da parceria ONU-EU, em criar uma arquitetura com informações, estratégias, orientaçóes e ferramentas que devem ser implantadas por Estados quando da identificação de possíveis conflitos violentos que envolvam os recursos naturais, materializa uma governança eficaz na prevenção e pacificação de conflitos, o que responde a segunda indagaçáo inicial da pesquisa.

A atuação das ONU e EU nas questóes referentes a prevenção de conflitos que envolve recursos naturais materializa o espírito da Declaraçáo de Estocolmo, pois esta declara que os Estados "devem assegurar-se de que as organizaçóes internacionais realizem um trabalho coordenado, eficaz e dinâmico na conservação e no melhoramento do meio ambiente", além de legitimar a importância da cooperação para formação de uma arquitetura de prevenção de conflitos. A parceria para consecução de seus fins produz soluçóes, que envolve a participação em rede de novos atores (sociedade civil, indústria, ciência) junto as Organizaçóes Internacionais pautado pela governança ambiental global.

\section{Conclusões}

1. O Direito Internacional Ambiental, regime recente do regramento jurídico internacional, aglutina uma normativa cada dia mais ampla, diversificada e complexa. Porém, para concretude de seu objetivo, que é a proteção do meio ambiente, é necessária cooperação em busca de soluçôes para os problemas graves que afetam o meio ambiente comum. Essa cooperação se materializa por meio da governança ambiental global. 
2. A governança ambiental compreende regras, práticas, políticas e instituiçóes que atuam em rede na busca de um objetivo comum, que é adequar a interação entre o homem e o meio ambiente. Embora o Direito Internacional Ambiental compartilhe com o Direito Internacional seus principais gerais elementos estruturais, em razão da peculiaridade de seu objeto, o meio ambiente, o Direito Internacional do Meio Ambiente apresenta características particulares como funcionalidade, multidimensionalidade, participação de atores não estatais e ampla presença de soft law na proteção de interesses gerais.

3. Diante da necessidade de fomentar a capacidade de governança das Organizaçóes Internacionais dentro do sistema ONU, surgiu o projeto de parceria entre a ONU e UE, no terreno de recursos naturais e prevençáo de conflitos. O projeto conjunto permite a coordenação do trabalho das agências e departamentos da ONU para ajudar os países a melhorar a gestão dos recursos naturais para prevenção dos conflitos e a criação de processos de paz.

4. A abordagem da parceria se baseia na compreensão de que os recursos naturais podem sustentar o desenvolvimento, promover estabilidade e determinar estilos de vida. No entanto, se esses recursos naturais forem mal geridos, podem desencadear baixo crescimento, corrupção, erosão da autoridade do Estado e conflitos destrutivos.

5. Para evitar este cenário, a aliança da ONU e UE fomenta a capacidade das Naçóes Unidas, União Europeia e seus países parceiros em prevenir, gerir e resolver conflitos relacionados a terra e aos recursos naturais, em busca de uma paz duradoura.

6. Dessa forma, fortalecer a capacidade das instituiçôes de governo e da sociedade civil relacionadas com a gestão dos conflitos da terra e dos recursos naturais é essencial para o êxito dos esforços de prevenção, recuperação e consolidação da paz.

7. Concluímos que a parceria entre a ONU e a UE permitiu bons resultados que estão materializados em um inventário de ferramentas e capacidades dentro do sistema das Naçóes Unidas e um conjunto de Notas de Orientação sobre a gestáo dos recursos naturais e prevenção de conflitos, acompanhado de materiais de treinamento e um módulo de formação on-line interativa, esses formam a arquitetura de prevenção que pode ser implanta pelos Estados. Os tópicos que abordam essas notas de orientação são a terra e os conflitos; as indústrias extrativas; os recursos renováveis e conflito; fortalecer a capacidade para gestão sustentável de terras e recursos naturais.

8. Assim, da análise da parceria de cooperação entre ONU-UE e do material produzido pelos atores envolvidos, conclui-se que é possível estabelecer uma metodologia que materialize os quatro ciclos de capacidade em prevenção de conflitos (informação, estratégia, implementação e aprendizado) em torno dos recursos naturais. As ações da cooperação podem ser consideradas hábeis a promover uma governança ambiental global em matéria de prevenção de conflitos. 


\section{Referências}

BEURIER, Jean-Pierre. Droit International de L'Environnement. Paris: Pedone, 2010.

BIERMAN, F; PATTBERG, P. Global Environmental Governance Reconsidered. Cambridge/London: The MIT Press, 2012.

CONFERENCIA DAS NAÇÓES UNIDAS. Declaraçáo de Estocolmo Sobre Meio Ambiente Humano. Junho de 1972.

GONÇALVES, Alcindo. Governança Global e o Direito Internacional Público. In: JUBILUT, L.iliana Lyra (coord.). Direito Internacional Atual. Rio de Janeiro: Ellsevier, 2014.

Governança Ambiental Global: possibilidades e limites. In: GRANZIERA, Maria Luiza Machado; REI, Fernando (coords.). Direito Ambiental Internacional. São Paulo: Atlas, 2015.

KISS, Alexandre; SHELTON, Dinah. Judicial handbook on environmental law. UNEP, 2005.

ONU. ASSEMBLEIA GERAL. Secretário Geral. A/66/811. Report on "Strengthening the role of mediation in the peaceful settlement of disputes, conflict prevention and resolution". Junho, 2012.

PADILHA, Norma Sueli. Fundamentos constitucionais do direito ambiental brasileiro. Rio de Janeiro: Elsevier, 2010.

PNUD. Equipo Marco Interinstitucional para la Acción Preventiva de la ONU. Kit de herramientas y orientación para la prevención y la gestión de conflictos de tierras y recursos naturales: Introducción y descripción general. Disponível em: http:// www.un.org/es/land-natural-resources-conflict/pdfs/GN_Capacity.pdf

. Equipo Marco Interinstitucional para la Acción Preventiva de la ONU. Kit de herramientas y orientación para la prevención y la gestión de conflictos de tierras y recursos naturales: Recursos renovables y conflitos. Disponível em: http:// www.un.org/es/land-natural-resources-conflict/pdfs/GN_Renew.pdf.

RUIZ, José Juste; DAUDÍ, Mireya Castillo. La protección del Medio ambiente em el Àmbito Internacional y em la Unión Europea. Valencia: Tirant lo Blanc, 2014.

UNEP. TANZLER, Dennis; ALTENBERG,Toolkit and guidance for preventing and managingland and natural resources conflict: capacity inventory. Jöran. Adelphi Research, Berlin 2010. Disponível em: http://www.un.org/es/land-natural-resources-conflict/pdfs/Capacity\%20Inventory.pdf.

. Environmental Governance, 2013. Disponível em: http://unep.org/pdf/brochures/EnvironmentalGovernance.pdf. 
. From Conflict to Peacebuilding: the Role of Natural Resources and the Environment, 2009. Disponível em: http://www.unep.org/pdf/pcdmb_policy_01. pdf.

. United Nations Department of Political Affairs. Natural resources and Conflict: A Guide for Mediation Practicioners, 2015. Disponível em: http://peacemaker. un.org/sites/peacemaker.un.org/files/NRCMediation_UNDPAUNEP2015_0.pdf.

UNITAR. Introduction to Environment, Natural Resources and UN Peacekeeping Operations. http://www.unitar.org/event/introduction-environment-natural-resources-and-un-peacekeeping-operations-ptp201503e. 